\title{
Relação entre o Consumo de Água e a AbsorÇão de Herbicidas em Plantas Daninhas e Cana-De-AçúCar ${ }^{1}$
}

\author{
Relationship between Water Consumption and Herbicide Absorption in Weeds and Sugarcane \\ ARALDI, R. ${ }^{2}$, VELINI, E.D. ${ }^{4}$, GIROTTO, M. ${ }^{2}$, CARBONARI, C.A. ${ }^{5}$, SAMPAIO, T.F. ${ }^{3}$ e \\ TRINDADE, M.L.B. ${ }^{5}$
}

\begin{abstract}
RESUMO - O objetivo deste trabalho foi avaliar a relação entre o consumo de água pelas plantas de cana-de-açúcar e plantas daninhas e a absorção de herbicidas. O trabalho foi desenvolvido em dois experimentos: no primeiro, mediu-se o consumo de água através da pesagem diária das espécies de plantas daninhas Digitaria horizontalis, Panicum maximum, Ipomoea grandifolia, Ipomoea hederifolia, Brachiaria decumbens, assim como para os cultivares de cana-deaçúcar PO8862, SP80 3280 e RB83 5486; e, no segundo, foram determinadas as concentrações do amicarbazone, imazapic, tebuthiuron e hexazinone no xilema dos três cultivares de cana-deaçúcar e de I. grandifolia por meio da bomba de Schollander e de cromatografia e espectrometria de massas (LC-MS). A taxa de transpiração e, consequentemente, a taxa de consumo de água mostraram-se determinantes da taxa de absorção de herbicidas pelas plantas de diferentes espécies de plantas daninhas e cultivares de cana-de-açúcar. As concentrações de herbicidas na seiva do xilema foram variáveis em função da espécie e do herbicida em contato com o sistema radicular, indicando que a facilidade de absorção pelas raízes pode ser determinante para eficácia e/ou seletividade de herbicidas.
\end{abstract}

Palavras-chave: bomba de Schollander, cromatografia, Saccharum officinarum, transpiração.

\begin{abstract}
The objective of this work was to evaluate the relationship between water consumption by sugarcane plants and weeds and herbicide absorption. Two experiments were carried out. In the first, water consumption was measured by daily weighing the weed species Digitaria horizontalis, Panicum maximum, Ipomoea grandifolia, Ipomoea hederifolia, Brachiaria decumbens, as well as the sugarcane cultivars PO8862, SP80 3280, and RB83 5486. In the second experiment, the concentrations of amicarbazone, imazapic, tebuthiuron and hexazinone in the xylem of the three sugarcane cultivars and I. grandifolia were measured using the Schollander pump and chromatography and mass spectrometry (LCMS). The transpiration rate and, consequently, the water consumption rate were determinants of the rate of herbicide absorption by the different weed species and sugarcane cultivars. The herbicide concentrations in the xylem sap varied according to the species and herbicide in contact with the root system, indicating that easy absorption by the roots can be crucial to the effectiveness and/or selectivity of herbicides.
\end{abstract}

Keywords: Schollander pump, chromatography, Saccharum officinarum, transpiration.

\section{INTRODUÇÃO}

A competição das plantas daninhas por água interfere e contribui para a redução da produtividade da cana-de-açúcar e de muitas outras culturas de interesse comercial, quando não controladas (Meckel et al., 1984). Essas plantas daninhas destacam-se quanto à rapidez e eficiência dos processos fisiológicos de transpiração. Procópio et al. (2004)

Recebido para publicação em 1.12.2010 e aprovado em 23.5.2011.

2 Pós-Graduação em Agronomia pela Faculdade de Ciências Agronômicas - FCA/UNESP, Campus de Botucatu, Fazenda Experimental Lageado, Caixa Postal 237, 18603-970 Botucatu-SP, <araldi@fca.unesp.br>; ${ }^{3}$ Pós-Graduação em Engenharia Florestal, FCA/UNESP, Campus de Botucatu; ${ }^{4}$ Professor, Dr., Dep. de Agricultura, FCA/UNESP, Campus de Botucatu; ${ }^{5}$ Doutores da FCA/UNESP, Campus de Botucatu, Núcleo de Pesquisa Avançada em Matologia (NUPAM). 
verificaram que Bidens pilosa e Euphorbia heterophylla apresentaram maior eficiência no uso da água e maior taxa de fotossintese líquida em relação à soja e ao feijão, nos estádios iniciais de crescimento.

Para evitar grandes competições das plantas daninhas tem-se o método químico, através do uso de herbicidas, como um dos métodos de controle mais utilizados nas áreas comerciais de cana-de-açúcar, sendo a seletividade a essa cultura a base para seu sucesso. Alguns cultivares de cana-de-açúcar apresentam respostas diferenciadas aos herbicidas, tendo como consequências problemas de fitotoxicidade e chegando a ocasionar redução na produtividade do canavial para os cultivares mais sensiveis. O comportamento diferenciado de cultivares de cana-de-açúcar diante de alguns herbicidas (Velini et al., 2000), associado ao estádio de desenvolvimento da cultura (Wixson \& Shaw, 1991), tem sido fator importante na tolerância de cultivares a herbicidas.

Quando as plantas estão transpirando ativamente, existe um fluxo contínuo de água das raízes até a parte aérea delas, sendo esse processo fundamental para que os herbicidas absorvidos pelas raízes sejam transportados até as folhas.

Em relação à absorção de herbicidas pelas raízes das plantas, combinada com a translocação pelo xilema, tem-se importância particular para herbicidas inibidores da fotossintese. Essa translocação dos herbicidas pelos tecidos vasculares é fundamental para que estes alcancem os sítios de ação, onde vão exercer sua atividade (Satichivi et al., 2000). Estudos de absorção de herbicida em solução foram conduzidos com o composto CNP (p-nitrofenil2,4,6-triclorofenil éter) em plantas de arroz, verificando-se maior absorção do CNP em plantas submetidas à solução, quando comparado com plantas cultivadas em solo (Shimotori \& Kuwatsuka, 1978).

Dessa forma, o conhecimento da eficiência do uso da água ajuda a selecionar as melhores plantas para determinadas condições (Olbrich et al., 1993). No caso da cana-deaçúcar, pensando apenas no aspecto do consumo de água relacionado com seletividade da cultura, um cultivar que consume menos água pode apresentar maior seletividade a alguns herbicidas, devido à menor translocação do produto até o local de ação na planta, tornandose mais interessante, diferentemente de um cultivar que consome mais água.

O objetivo deste trabalho foi avaliar a relação entre o consumo de água pelas plantas de cana-de-açúcar e plantas daninhas e a absorção de herbicidas.

\section{MATERIAL E MÉTODOS}

Na avaliação da taxa de transpiração foram utilizados os cultivares de cana-de-açúcar PO 8862, SP80 3280 e RB83 5486, sendo respectivamente caracterizadas como cultivares de baixa, média e alta sensibilidade aos herbicidas, assim como as espécies de plantas daninhas $B$. decumbens (capim-braquiária), I. grandifolia (corda-de-viola), I. hederifolia (corda-de-viola), P. maximum (capim-colonião) e $D$. horizontalis (capim-colchão).

As plantas foram cultivadas em vasos contendo substrato em casa de vegetação; 30 dias após o plantio e/ou semeadura, elas, com cerca de quatro folhas, foram cuidadosamente coletadas e tiveram suas raizes lavadas. As plantas daninhas foram colocadas isoladas em recipientes plásticos de $50 \mathrm{~mL}$, e a cana-de-açúcar, em recipientes plásticos de $500 \mathrm{~mL}$ com água. Foram isoladas as superficies dos recipientes com papel-alumínio, a fim de evitar a evaporação e garantir que a única saída de água do sistema fosse pela transpiração. Para aferir a eficiência do método em evitar a evaporação de água, foi mantido frasco (50 e $500 \mathrm{~mL}$ ) com água e papel-alumínio. O consumo de água foi mensurado pela pesagem diária dos recipientes. No caso da cana-de-açúcar, foi necessária a aeração do sistema (fornecimento de oxigênio) para manter as plantas em condições normais de metabolismo. O experimento foi instalado em delineamento inteiramente casualizado com 10 repetições, tendo como tratamento os três cultivares de cana-de-açúcar (PO 8862, SP80 3280 e RB83 5486) e cinco espécies daninhas (D. horizontalis, $P$. maximum, I. grandifolia, I. hederifolia e B. decumbens).

As plantas foram mantidas em câmara climatizada com condições controladas de temperatura e umidade relativa: entre 25 e $30{ }^{\circ} \mathrm{C}$ e $60 \%$, respectivamente. 
Para as avaliações de consumo de água das plantas, foi definido um período de três dias de monitoramento da transpiração; após essas avaliações, foi determinada a área foliar das plantas através do equipamento Area Meter (LI-COR 3100). Na sequência, foi calculado o consumo de água médio dos três dias, $\mathrm{em} \mathrm{cm}^{3}$ $\mathrm{cm}^{-2}$ de planta.

Para os resultados de consumo de água por área foliar das plantas daninhas, foi estabelecido o intervalo de confiança pelo teste t a $10 \%$ de probabilidade. Para determinar o intervalo de confiança, foi utilizada a seguinte equação:

$I C=\frac{(t \cdot d e s v p a d)}{\sqrt{n r}}$

em que $I C=$ intervalo de confiança; $t=$ valor de $t$ tabelado, a 10\% de probabilidade; desvpad $=$ desvio-padrão; $\mathrm{e} \sqrt{n r}=$ raiz quadrada do número de repetições.

Para os cultivares de cana-de-açúcar, foi desenvolvido o cálculo do consumo de água por $\mathrm{cm}^{2}$, através da área do trapézio gerada por meio da regressão linear descrita na Figura 1. O cálculo do consumo de água por área foliar (CAPAF) em $\mathrm{cm}^{3} \mathrm{~cm}^{-2}$ das plantas avaliadas foi determinado através da equação (1), com os parâmetros demonstrados na Figura 1. Os coeficientes foram determinados pela regressão linear estabelecida a partir dos dados coletados, sendo o eixo y representado pelo consumo de água médio por dia $(\mathrm{CA}) \mathrm{em}^{3} \mathrm{~cm}^{3}$ o eixo $\mathrm{x}$, pela área foliar (AF) em $\mathrm{cm}^{2}$ (Figuras 2 a 4). Houve necessidade de uso dos modelos

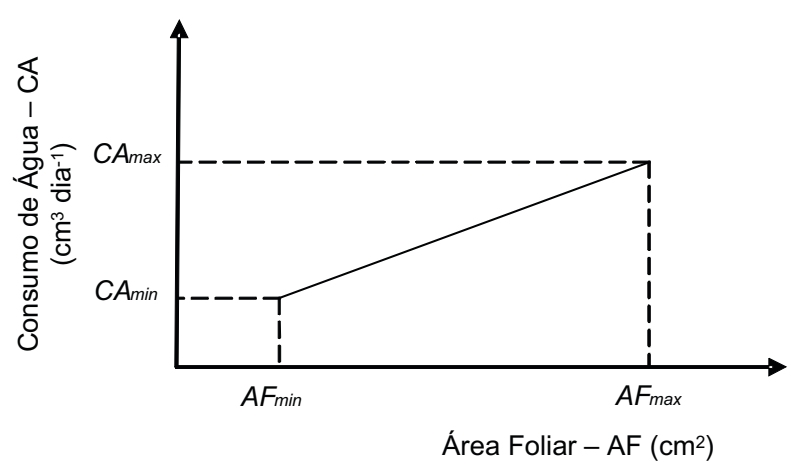

Figura 1 - Parâmetros da equação 1 para determinar o consumo de água da cana-de-açúcar. Botucatu-SP - 2010.

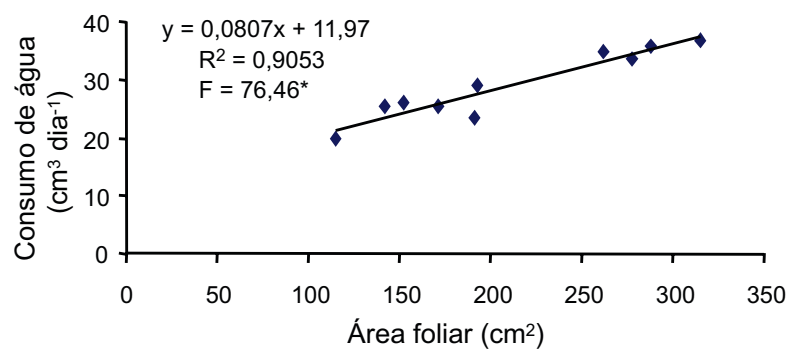

Figura 2 - Regressão linear entre consumo de água e área foliar para o cultivar PO8862 de cana-de-açúcar. Botucatu-SP 2010 .

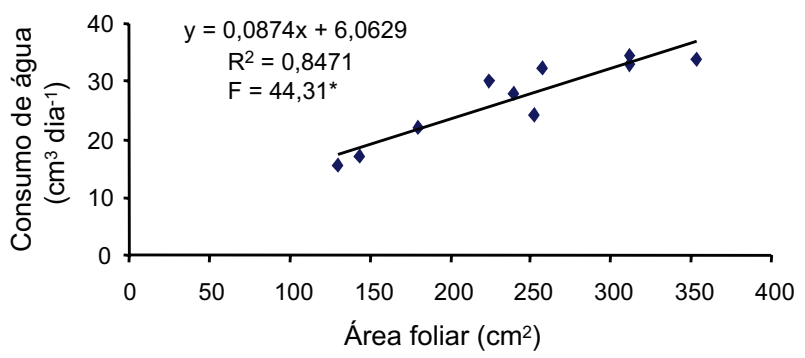

Figura 3 - Regressão linear entre consumo de água e área foliar para o cultivar SP80 3280 de cana-de-açúcar. Botucatu-SP 2010 .



Figura 4 - Regressão linear entre consumo de água e área foliar para o cultivar RB83 5486 de cana-de-açúcar. Botucatu-SP $-2010$.

em função da grande variação do tamanho das plantas utilizadas no ensaio. Foram calculadas as curvas que representam o intervalo de confiança do modelo utilizado a $10 \%$ de probabilidade.

A padronização dos dados dos cultivares de cana-de-açúcar foi realizada, para que os valores de CAPAF avaliados fossem interceptados na mesma área do gráfico.

Foi utilizada a equação a seguir para determinar o consumo de água $\mathrm{em} \mathrm{cm}^{3} \mathrm{~cm}^{-2}$ para cana-de-açúcar. 
$\operatorname{CAPAF}\left(\mathrm{cm}^{3} / \mathrm{cm}^{2}\right)=\frac{\left(\frac{C A_{\text {max }}+C A_{\text {min }}}{2}\right) x\left(A F_{\text {max }}-A F_{\text {min }}\right)}{\left(\frac{A F_{\text {max }}+A F_{\min }}{2}\right) x\left(A F_{\text {max }}-A F_{\text {min }}\right)} .:$

$\operatorname{CAPAF}\left(\mathrm{cm}^{3} / \mathrm{cm}^{2}\right)=\frac{\left(\frac{C A_{\text {max }}+C A_{\text {min }}}{2}\right)}{\left(\frac{A F_{\text {max }}+A F_{\text {min }}}{2}\right)}$

Um segundo estudo foi conduzido com os mesmos cultivares de cana-de-açúcar (PO8862, SP80 3280 e RB83 5486) e uma espécie de planta daninha: I. grandifolia. As plantas foram mantidas nas condições controladas da câmara climatizada. De forma semelhante à determinação do consumo de água, após a lavagem das raízes das plantas, estas foram colocadas em soluções contendo amicarbazone $\left(0,240 \mathrm{mg} \mathrm{L}^{-1}\right)$, hexazinone $\left(0,252 \mathrm{mg} \mathrm{L}^{-1}\right)$, tebuthiuron $\left(0,228 \mathrm{mg} \mathrm{L}^{-1}\right) \mathrm{e}$ imazapic $\left(0,283 \mathrm{mg} \mathrm{L}^{-1}\right)$.

Nessa etapa, foram utilizados quatro tratamentos com cinco repetições em delineamento inteiramente casualizado, sendo quatro espécies (três cultivares de cana-deaçúcar e I. grandifolia) e quatro herbicidas (amicarbazone, imazapic, tebuthiuron e hexazinone).

Na instalação do experimento foram utilizadas em complemento quatro plantas como marcadoras para cada espécie, sendo disponibilizado o corante Rhodamina B em solução (concentração de 1.000 ppm) com o objetivo de verificar o momento indicativo da translocação dos compostos para a parte aérea das plantas, assim como da movimentação dos herbicidas. Assim, foi fixado um intervalo de 40 horas entre o contato do sistema radicular com a solução contendo os herbicidas e a extração da seiva. Apenas I. grandifolia foi mantida por um período de 20 horas após o contato com a solução, visto que foi marcada mais rapidamente pelo corante. Também foi calculado o consumo de água (transpiração) das plantas, com a diferença do peso inicial e final do experimento, conforme anteriormente descrito, como forma de garantir que houve condições para que o herbicida tenha sido absorvido e translocado nas plantas.

Após o intervalo de tempo fixado para as plantas absorverem os herbicidas da solução, elas foram colocadas na bomba de Schollander para extração da seiva (Scholander et al., 1965), assim como para verificar a absorção dos herbicidas. A pressão hidrostática incidida na câmara pode ser aplicada até aparecer uma gota de água na superficie do corte, registrando assim a pressão hídrica da planta (Liang et al., 1996); com o incremento na pressão foi possivel coletar a seiva de plantas na superficie cortada.

Para os três cultivares de cana-de-açúcar, foram utilizadas as folhas para extração da seiva. Já para a planta daninha utilizou-se toda a parte aérea da planta. Com o auxílio de uma pipeta Pasteur, a seiva foi coletada da folha ou caule das plantas e colocada em vails para posteriores análises cromatográficas.

As concentrações dos herbicidas na seiva do xilema das plantas em estudo foram determinadas por cromatografia e espectrometria de massas (LC-MS). O método analítico da quantificação dos herbicidas foi desenvolvido em cromatógrafo líquido da marca Shimadzu ${ }^{\circledR}$, equipado com software Class VP 6.0, bomba quaternário LC $20 \mathrm{AD}$, degaseificador DGU 20AS, injetor automático SIL $10 \mathrm{AF}$, forno CTO 10ASVP e detector de massas LCMS-2010 EV.

Para as análises cromatográficas, foi empregada coluna de C18, marca Synergi ${ }^{\circledR}$

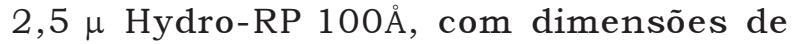
50 x 4,6 mm e volume de injeção de $30 \mu \mathrm{L}$. As análises foram efetuadas em modo gradiente, tendo como fases móveis os solventes metanol e água com ácido acético até atingir $\mathrm{pH} 2,8$. A proporção entre os solventes teve início com 60:40 (metanol:água); aos quatro minutos, chegou a 95:5; e retornou à condição inicial aos sete minutos. O tempo total de corrida foi de $15 \mathrm{~min}$, e o de retenção, de 2,33, 2,65, 2,91 e 2,63 min para amicarbazone, imazapic, tebuthiuron e hexazinone, respectivamente. Foram estabelecidos seis pontos para curva de calibração, sendo empregada a quantificação em diferentes concentrações dos padrões dos herbicidas.

A partir das áreas dos picos cromatográficos e concentrações das soluções de padrões analiticos dos herbicidas, foram estabelecidos os seguintes parâmetros: equação linear de regressão; coeficiente de correlação; 
coeficiente de determinação; linearidade; limite de detecção; e limite de quantificação do método, segundo os procedimentos descritos por Meier \& Zund (1993). Esses parâmetros estimaram a confiabilidade do método analítico.

As concentrações dos herbicidas na seiva de xilema foram expressas em porcentagem da concentração dos herbicidas, disponibilizados em solução para as plantas. Por meio desses resultados foi estabelecido o intervalo de confiança pelo teste t a $10 \%$ de probabilidade, conforme anteriormente descrito.

\section{RESULTADOS E DISCUSSÃO}

De maneira geral, as plantas daninhas consumiram mais água por $\mathrm{cm}^{2}$ do que as plantas de cana-de-açúcar, o que indica maior competitividade por água das plantas invasoras (Tabela 1). De acordo com Meckel et al. (1984), a competição por água das plantas daninhas contribui para redução da produtividade da cana-de-açúcar e de outras culturas.

Entre as plantas daninhas, a que mais se destacou pelo consumo de água foi D. horizontalis $\left(0,3630 \mathrm{~cm}^{3} \mathrm{~cm}^{-2}\right)$, enquanto I. hederifolia foi a que apresentou o menor consumo de água $\left(0,1542 \mathrm{~cm}^{3} \mathrm{~cm}^{-2}\right)$. Ou seja,

Tabela 1 - Consumo de água $\left(\mathrm{cm}^{3} \mathrm{~cm}^{-2}\right)$ para os cultivares de cana-de-açúcar PO8862, SP80 3280 e RB83 5486 e para as plantas daninhas D. horizontalis, P. maximum, B. decumbens, I. grandifolia e I. hederifolia. Botucatu-SP $-2010$

\begin{tabular}{|l|c|}
\hline \multicolumn{1}{|c|}{ Espécie } & $\begin{array}{c}\text { Consumo de água } \\
\left(\mathrm{cm}^{3} \mathrm{~cm}^{-2}\right)\end{array}$ \\
\hline D. horizontalis & $0,3630 \pm 0,0497^{1 /}$ \\
\hline Panicum maximum & $0,2630 \pm 0,0305$ \\
\hline Ipomoea grandifolia & $0,2576 \pm 0,0473$ \\
\hline Brachiaria decumbens & $0,2205 \pm 0,0251$ \\
\hline Ipomoea hederifolia & $0,1542 \pm 0,0226$ \\
\hline Cana-de-açúcar (PO8862) $)^{2 /}$ & $0,1623 \pm 0,0534$ \\
\hline Cana-de-açúcar (SP80 3280) & $0,1287 \pm 0,0820$ \\
\hline Cana-de-açúcar (RB83 5486) & $0,1152 \pm 0,0618$ \\
\hline
\end{tabular}

$\underline{1}$ / Foi utilizado o intervalo de confiança a $10 \%$ de probabilidade

2/ Para cana-de-açúcar, os valores encontrados foram com base nos cálculos de área gerados da relação entre consumo de água $\left(\mathrm{cm}^{3}\right)$ e área foliar $\left(\mathrm{cm}^{2}\right)$ uma diferença de 2,3 vezes de consumo de água entre ambas. Uma resposta intermediária quanto ao consumo de água ocorreu em $P$. maximum, $B$. decumbens e I. grandifolia, com consumo de 0,2630, 0,2576 e 0,2205 $\mathrm{cm}^{3}$ $\mathrm{cm}^{-2}$, respectivamente. I. grandifolia teve um consumo $1,7 \mathrm{vez}$ maior do que o de I. hederifolia.

Os valores de consumo de água encontrados para os cultivares de cana-de-açúcar foram decrescentes para PO8862, SP80 3280 e RB83 5486. A seletividade de cana-de-açúcar aos herbicidas pode estar associada ao menor consumo de água pelas plantas dessa cultura, visto que o cultivar sensivel aos herbicidas (PO8862) foi o que consumiu mais água quando comparado com o cultivar intermediária, SP80 3280, e o tolerante, RB83 5486, de menores consumos. De acordo com Olbrich et al. (1993), o conhecimento da eficiência do uso da água pode ajudar a selecionar as melhores plantas para determinadas condições.

Comparando com a média dos três cultivares de cana-de-açúcar, D. horizontalis, $P$. maximum e I. grandifolia consumiram, respectivamente, $2,7,2,0$, e 2,0 vezes mais água do que essa cultura. Jones Júnior \& Walker (1993) também observaram que a absorção de água por Xanthium strumarium superou em duas vezes a quantidade de água consumida pela soja. Procópio et al. (2004) verificaram que as espécies Bidens pilosa e Euphorbia heterophylla apresentaram maior eficiência no uso da água em relação à soja e ao feijão, nos estádios iniciais de crescimento. Dalley et al. (2006), trabalhando com milho, observaram maior eficiência de absorção e aproveitamento de água pelas plantas daninhas.

Com relação às concentrações dos herbicidas estudados na seiva do xilema, os maiores valores indicam menores restrições à absorção do herbicida, enquanto valores menores indicam maiores restrições à absorção e translocação do composto (Tabela 2). De acordo com esses dados, uma análise preliminar indica que maiores concentrações relativas de herbicida em seiva de xilema provavelmente estarão associadas a maiores niveis de sensibilidade da planta ao herbicida. 
Tabela 2 - Relação em porcentagem entre as concentrações de herbicidas na seiva de xilema e na solução fornecida ao sistema radicular para os cultivares de cana-de-açúcar PO8862, SP80 3280 e RB83 5486 e para I. grandifolia. Botucatu-SP - 2010

\begin{tabular}{|l|c|c|c|c|}
\hline \multirow{2}{*}{ Herbicida } & \multicolumn{3}{|c|}{ Cana-de-açúcar (\%) } & \multirow{2}{*}{ I. grandifolia (\%) } \\
\cline { 2 - 5 } & PO8862 & SP80 3280 & RB83 5486 & $53,86 \pm 13,47$ \\
\hline amicarbazone & $5,22 \pm 3,23^{1 /}$ & $6,13 \pm 2,82$ & $4,70 \pm 1,04$ & $24,48 \pm 5,44$ \\
\hline imazapic & $5,00 \pm 2,54$ & $4,41 \pm 2,06$ & $1,73 \pm 0,98$ & $26,49 \pm 6,57$ \\
\hline tebuthiuron & $5,88 \pm 3,55$ & $5,29 \pm 1,43$ & $0,46 \pm 0,79$ & $23,87 \pm 5,73$ \\
\hline hexazinone & $4,90 \pm 2,28$ & $4,15 \pm 0,67$ & $3,41 \pm 0,39$ & \\
\hline
\end{tabular}

1// Valores calculados através do intervalo de confiança a $10 \%$ de probabilidade.

Quanto aos teores dos herbicidas na seiva do xilema expressos em porcentagem das concentrações iniciais colocadas em contato com as raízes, observa-se que $I$. grandifolia foi a que apresentou os maiores valores médios para os quatro herbicidas testados, com destaque para o amicarbazone, para o qual a diferença em relação à cana-de-açúcar foi da ordem de dez vezes. Considerando os cultivares de cana-deaçúcar, os menores valores de teores de herbicidas em seiva, para os quatro herbicidas, foram observados para o cultivar RB83 5486, indicando menor absorção dos compostos e, possivelmente, maior tolerância a estes. De acordo com Procópio et al. (2008), o cultivar RB83 5486 é considerado de baixa sensibilidade aos herbicidas de maneira geral.

Para as concentrações de imazapic, tebuthiuron e hexazinone nas plantas, foi verificado que I. grandifolia apresentou cinco vezes mais herbicidas em seiva de xilema do que os cultivares PO8862 e SP80 3280. Já o cultivar RB83 5486 apresentou mínimas concentrações dos herbicidas em seiva de xilema.

As maiores diferenças entre os teores médios de herbicidas na seiva do xilema nas raizes da planta daninha e dos cultivares de cana-de-açúcar foram observadas para o amicarbazone. Em geral, os maiores valores de herbicidas estiveram associados ao maior consumo de água determinado no estudo anterior. Considerando o amicarbazone, para o consumo de água e para as concentrações na seiva de xilema, pode-se pressupor que I. grandifolia transpira mais e tem maior capacidade de absorver amicarbazone, indicando um possivel grau elevado de sensibilidade da espécie ao herbicida quando comparado com os cultivares de cana-de-açúcar.
Considerando o produto entre as duas variáveis (consumo de água e concentrações na seiva de xilema), é possivel estabelecer a seguinte sequência dos cultivares de canade-açúcar quanto à sensibilidade ao herbicida amicarbazone: PO8862, SP80 3280 e RB83 5486. Também o imazapic, tebuthiuron e hexazinone seguem essa mesma sequência de sensibilidade dos cultivares de cana-deaçúcar.

De maneira geral, pode-se observar que a taxa de transpiração e, consequentemente, o consumo de água mostraram-se importantes para compreensão da taxa de absorção de herbicidas para plantas de diferentes espécies e cultivares.

As concentrações de herbicidas na seiva do xilema foram bastante variáveis em função da espécie e do herbicida, indicando que a facilidade de absorção pelas raízes pode ser determinante para a eficácia e/ou seletividade de herbicidas.

\section{LITERATURA CITADA}

DALLEY, C. D.; BERNARDS, M. L.; KELLS, M. J. Effect of water removal timing and row spacing on soil moisture in corn (Zea mays). Weed Ecol., v. 20, n. 2, p. 399-409, 2006.

JONES JÚNIOR, R. E.; WALKER, R. H. Effect of interespecific, light intensity, and soil moisture on soybean (Glycine max), common cockbleur (Xanthium strumarium), and sicklepod (Senna obtusifolia) water uptake. Weed Sci., v. 41, n. 4 , p. $534-540,1993$

LIANG, J.; ZHANG, J.; WONG, M. H. Stomatal conductance in relation to xylem sap ABA concentration in two tropical trees: Acacia confuse and Litsea glutinosa. Plant Cell Environ., v. 19, n. 1, p. 93-100, 1996. 
MECKEL, L. D. et al. Effect of moisture stress on seed growth in soybeans. Agron. J., v. 76, n. 4, p. 647-650, 1984.

MEIER, P. C.; ZUND, R. E. Statistical methods in analytical chemistry. New York, John Wiley \& Sons, 1993. p. 105.

OLBRICH, B. W.; ROUX, D. L. E.; POULTER, A. G. Variation in water use efficiency and $\mathrm{G}^{13} \mathrm{C}$ levels in Eucalyptus grandis clones. J. Hydrol., v. 150, n. 15, p. 615-633, 1993.

PROCÓPIO, S. O. et al. Características fisiológicas das culturas de soja e feijão e de três espécies de plantas daninhas. Planta Daninha, v. 22, n. 2, p. 211-216, 2004.

PROCÓPIO, S. O.; SILVA, A. A.; VARGAS, L. Manejo e controle de plantas daninhas em cana-de-açúcar. In: VARGAS, L.; ROMAN, E. S. (Eds.). Manual de manejo e controle de plantas daninhas. Passo Fundo: Embrapa Trigo, 2008. $780 \mathrm{p}$.
SATICHIVI, N. M. et al. Absorption and translocation of glyphosate isopropylamine and trimethysulfonium salts in Abutilon theophrasti and Setaria faberi. Weed Sci., v. 48, n. 6, p. 675-679, 2000.

SHIMOTORI, H.; KUWATSUKA, S. Absorption, translocation and metabolism d CNP, a diphenyl ether herbicide, and its amino derivate in rice plants. J. Pestic., v. 3, n. 3 , p. $267-275,1978$.

SCHOLANDER, P. F. et al. Sap pressure in vascular plants. Science, v. 148, n. 3, p. 339-346, 1965.

VELINI, E. D. et al. Avaliação da seletividade da mistura de oxyfluorfen e ametryne, aplicada em pré e pós-emergência, a dez variedades de cana-de-açúcar (cana-planta).

Planta Daninha, v. 18, n. 2, p. 123-134, 2000.

WIXSON, M. B.; SHAW, D. R. Use of AC 263,222 for sicklepod (Cassia obtusifolia) control in soybean (Glycine max). Weed Technol., v. 5, n. 2, p. 276-279, 1991. 